QUARTERLY TECHNICAL PROGRESS REPORT

NTIMEER 20

THE ECONOMICAI, PRODUCTION OF

ALCOHOI FUEIS FROM

COAL-DERIVED SYNTHESIS GAS

CONTRACT NO. DE-AC22-91PC91034

RECEIVED

\section{REPORTING PERIOD:}

July 1, 1996 to September 30, 1996
FFR 101998

OSTI

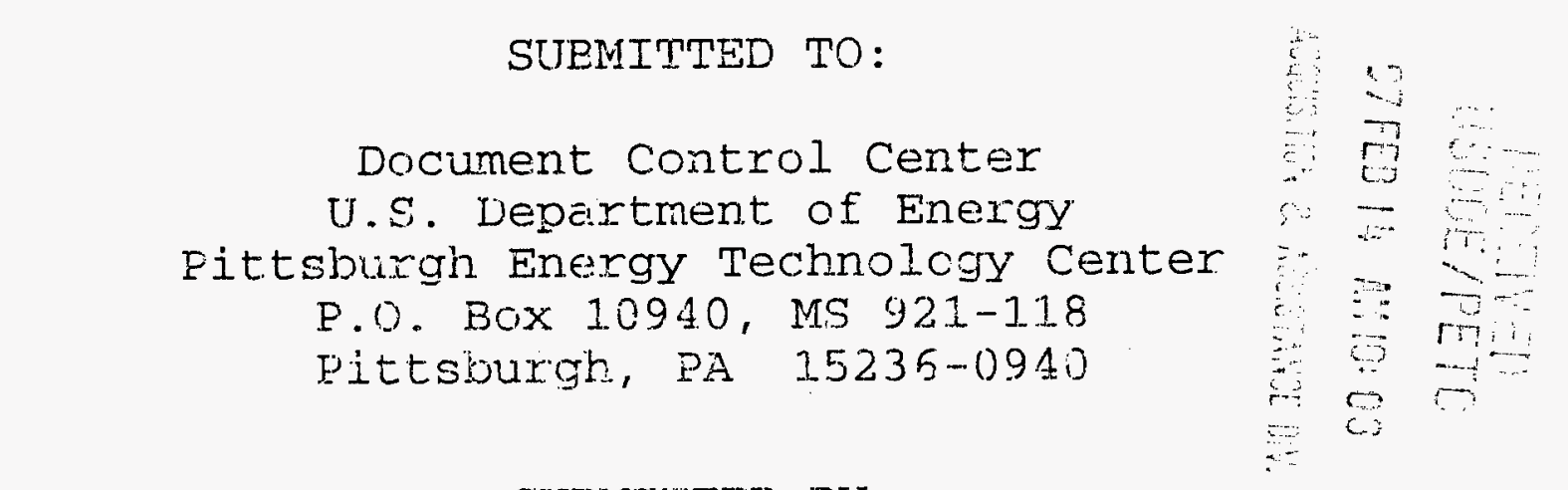

\title{
SUBSITITED EY:
}

West Virginia University kesearch Corpcration on behalf of West Virginia University

885 Chestnut Ridge Road

Morgantown, Wr 26506

cctober, 1996

U.S. DOE Patent Ciearance is not requireci prior to the publication of this document. 


\section{DISCLAIMER}

This report was prepared as an account of work sponsored by an agency of the United States Government. Neither the United States Government nor any agency thereof, nor any of their employees, makes any warranty, express or implied, or assumes any legal liability or responsibility for the accuracy, completeness, or usefulness of any information, apparatus, product, or process disclosed, or represents that its use would not infringe privately owned rights. Reference herein to any specific commercial product, process, or service by trade name, trademark, manufacturer, or otherwise does not necessarily constitute or imply its endorsement, recommendation, or favoring by the United States Government or any agency thereof. The views and opinions of authors expressed herein do not necessarily state or reflect those of the United States Government or any agency thereof. 
QUARTERLY TECHNICAL PROGRESS REPORT

NUMBER 20

THE ECONOMICAL PRODUCTION OF

ALCOHOL FUELS FROM

COAL-DERIVED SYNTHESIS GAS

CONTRACT NO. DE-AC22-91PC91034

\section{REPORTING PERIOD:}

July 1, 1996 to September 30, 1996

$$
\text { SUBMITTED TO: }
$$

Document Control Center

U.S. Department of Energy

Pittsburgh Energy Technology Center

P.O. Box 10940, MS 921-118

Pittsburgh, PA 15236-0940

\section{SUBMITTED BY:}

West Virginia University Research Corporation on behalf of West Virginia University

886 Chestnut Ridge Road

Morgantown, WV 26506

\section{October, 1996}

U.S. DOE Patent Clearance is not required prior to the publication of this document. 


\section{TABLE OF CONTENTS}

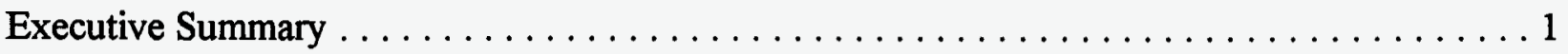

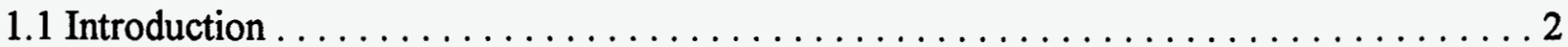

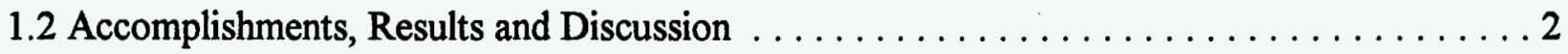

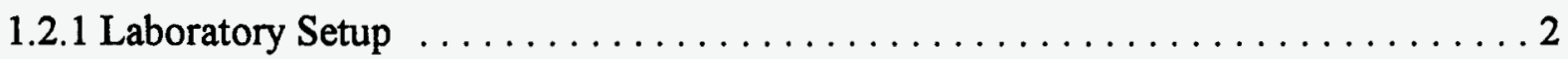

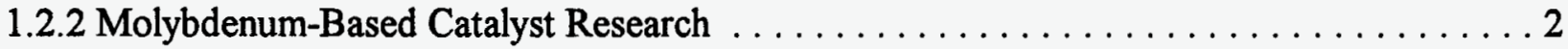

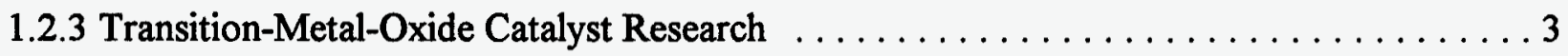

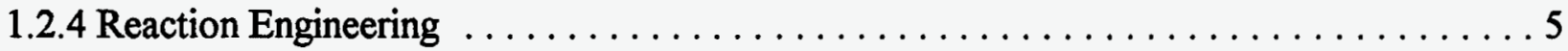

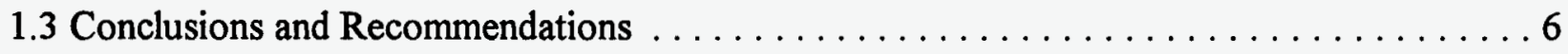

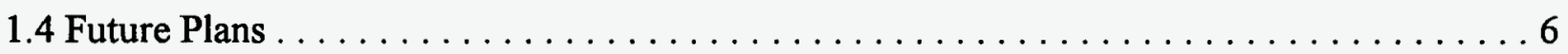

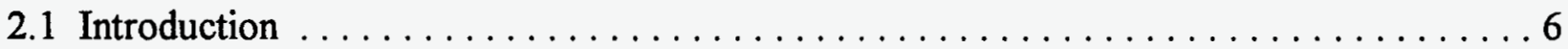

2.2 Accomplishments, Results, and Discussion $\ldots \ldots \ldots \ldots \ldots \ldots \ldots \ldots \ldots \ldots \ldots \ldots \ldots \ldots \ldots$

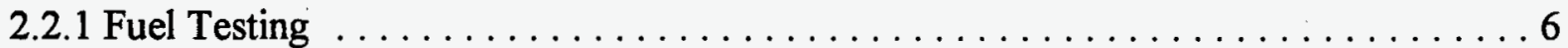

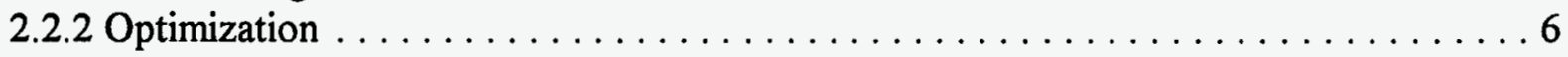

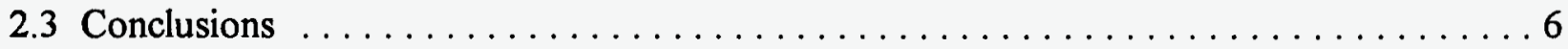

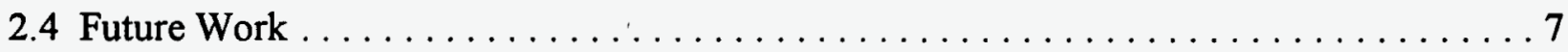




\section{Executive Summary}

During this time period, at WVU, we have obtained models for the kinetics of the HAS reaction over the Co-K-MoS $/ \mathrm{C}$ catalyst. The Rotoberty reactor was then replaced in the reactor system by a plug-flow tubular reactor. Accordingly, we re-started the investigations on sulfide catalysts. We encountered and solved the leak problem from the sampling valve for the non-sulfided reactor system. We also modified the system to eliminate the condensation problem. Accordingly, we are continuing our kinetic studies on the reduced Mo-Ni-K/C catalysts. We have set up an apparatus for temperature-programmed reduction (TPR) studies, and have obtained some interesting results on TPR characterizations.

At UCC, the complete characterization of selected catalysts has been started. We sent nine selected types of $\mathrm{ZnO}, \mathrm{Zn} / \mathrm{CrO}$ and $\mathrm{Zn} / \mathrm{Cr} / \mathrm{MnO}$ catalysts and supports for BET surface area, SEM, $\mathrm{XRD}$ and ICP. We also sent fresh and spent samples of the Engelhard $\mathrm{Zn} / \mathrm{CrO}$ catalyst impregnated with $3 \mathrm{wt} \%$ potassium for ISS and XPS testing.

In Task 2, work on the design and optimization portion of this task, as well as on the fuel testing, is completed. All funds have been expended and there are no personnel working on this project. 


\subsection{Introduction}

The objective of Task 1 is to prepare and evaluate catalysts and to develop efficient reactor systems for the selective conversion of hydrogen-lean synthesis gas to alcohol fuel extenders and octane enhancers.

Task 1 is subdivided into three separate subtasks: laboratory and equipment setup; catalysis research; and reaction engineering and modeling. Research at West Virginia University (WVU) is focused on molybdenum-based catalysts for higher alcohol synthesis (HAS). Parallel research carried out at Union Carbide Corporation (UCC) is focused on transition-metal-oxide catalysts.

\subsection{Accomplishments, Results and Discussion}

\subsubsection{Laboratory Setup}

During this reporting period, we replaced the Rotoberty reactor, which was used for kinetic studies of a sulfided carbon-supported K-doped Mo-Co catalyst, with a plug-flow tubular reactor. This reactor was used to study the effect of sulfur on the performance of non-sulfided catalysts and to carry out investigations on sulfided catalysts.

We encountered a leak problem from the sampling valve for the non-sulfided reactor system. This was solved by replacing with a new type of valve rated at $1000 \mathrm{psig}$ at $250^{\circ} \mathrm{C}$. We also added a hot trap right before the sampling valve to eliminate the condensation problem in the sampling loop and in the $\mathrm{GC}$ carrier gas line. A reduced Mo-Ni-K/C catalyst is being run to verify the effectiveness of the modification.

We have set up an apparatus for TPR studies. The schematic diagram was shown in MS59.

\subsubsection{Molybdenum-Based Catalyst Research}

At WVU, the focus of the experimental program has been the TPR characterization of the carbonsupported Mo-based catalysts. The carbon support itself was first studied, followed by the Kimpregnated carbon support and $\mathrm{Mo}-\mathrm{K} / \mathrm{C}$ as well as $\mathrm{Ni}-\mathrm{K} / \mathrm{C}$ catalysts. Detailed results have been presented in MS60 and MS61.

After the Rotoberty reactor was converted to a tubular reactor, a reduced Mo-Ni-K/C catalyst and a BASF methanol synthesis catalyst were run on the system, to evaluate the effect of sulfided reactor system on the catalytic performances. It was found that the sulfided reactor system has a nonnegligible effect on the catalytic performances, both on the selectivity and the activity. Therefore, this system is supposed to be used only for sulfur-resisting catalysts. Subsequently, a sulfided Mo-Ni-K/C catalyst was run on the system, and it was shown that the performance of the sulfided Mo-Ni-K/C catalyst is not as good as that of a reduced one. Details have been given in MS61.

As noted above, for the non-sulfided reactor system, we encountered a leak problem and a 
condensation problem. The leak problem has been solved and the condensation problem remains to be resolved. We are still considering continuing the design experiment on the reduced Mo-Ni-K/C catalysts, to obtain a kinetic model to describe the catalytic performance.

We have obtained models for the kinetics of the HAS reaction over the Co-K-MoS $/ \mathrm{C}$ catalyst in the Rotoberty reactor. The experimental data have been tabulated in MS59. Power-law rate equations have been developed for the rates of hydrocarbons, ethanol, and propanol, to determine the statistically significant variables for each. (It is not possible to develop a similar model for methanol, since the rate of formation was negative in cases where methanol was added as a reactant.) The independent variables considered for the rate of ethanol were the temperature, the partial pressures of $\mathrm{CO}, \mathrm{H}_{2}$, inerts and $\mathrm{MeOH}$, and the catalyst age. Similar variables were used for the rate of propanol, except that ethanol was used in place of methanol. Since individual hydrocarbons were not identified, a single rate expression has been developed for these, and the hydrocarbons are assumed to have the properties of methane, the most abundant species. We further assumed that methane is produced from an intermediate formed by the adsorption of methanol. Hence, the partial pressure of methanol was used as an independent variable, along with the temperature, catalyst age, and partial pressures of $\mathrm{CO}, \mathrm{H}_{2}$ and inerts. The "gross" rates of production were used in the model, e.g,, for ethanol production, the sum of the observed ("net") rates of formation of ethanol and propanol were used. This is because the higher alcohols can be considered to be produced from a sequential mechanism, in which ethanol is formed from methanol, propanol from ethanol, and so on.

For each of the power-law models, a regression analysis has been performed. The significance of each model has been tested using the F-statistic. Student's $t$ test is used to test the significance of the parameter estimates.A summary of the parameters has been provided in MS60. Qualitatively, all the data for the Co- $-\mathrm{MoS}_{2}$ catalyst appear to correlate best with the partial pressure of the corresponding precursor, and with temperature. Catalyst age appears to play at best a small role.

\subsubsection{Transition-Metal-Oxide Catalyst Research}

At UCC, the characterization studies focussed on (a) the differences among catalyst supports and (b) changes in the catalyst structure during testing.

Regarding the catalyst supports, ICP analysis confirmed the relative ratios of the chemical constituents used to manufacture the catalysts. The Engelhard support (which, of course, we did not manufacture) contained $62 \% \mathrm{Zn}$ and $16 \% \mathrm{Cr}$. For comparison, the UCC stoichiometric $\mathrm{ZnCrO}$ sample contained $23 \% \mathrm{Zn}$ with $34 \% \mathrm{Cr}$. Thus, the Engelhard support included excess $\mathrm{Zn}$, and might be expected to show a $\mathrm{ZnO}$ phase in other analyses.

BET surface analysis indicated that $\mathrm{ZnO}$ samples had lower surface areas than those mixed with $\mathrm{Cr}$ or $\mathrm{Mn}$. However the presence of excess $\mathrm{Zn}$ in $\mathrm{ZnCrO}$ samples did not significantly affect the surface area. Stoichiometric $\mathrm{ZnCrMnO}$ catalyst exhibited the highest surface area at 162 square meters per gram.

SEM analysis did not help explain why the stoichiometric $\mathrm{ZnCrMnO}$ had such a high BET surface 
area. It was not obvious from SEM that its particles were significantly different from other UCCmanufactured catalysts at magnifications of x100 to x10,000. However, it was clear that particle sizes were smaller for UCC $\mathrm{ZnO}$ than the Aldrich $\mathrm{ZnO}$, and that uncalcined Engelhard catalyst had smaller particles than calcined Engelhard catalyst. These observations agreed with BET results.

$\mathrm{XRD}$ analysis showed that $\mathrm{ZnO}$ was an important phase in all catalyst samples except the UCC stoichiometric catalysts. The stoichiometric zinc-chrome catalyst formed a zincochromite phase as intended. Interestingly, when we used excess zinc, a different zinc-chrome oxide phase was formed in addition to zinc oxide, and no zincochromite was evident. The Engelhard $\mathrm{ZnCrO}$ catalyst had phases similar to our UCC excess zinc catalysts. The stoichiometric zinc-chrome-manganese oxide catalyst had no $\mathrm{ZnO}$ phase, but we did not have the spinel in our database. When we added excess zinc to the zinc-chrome-manganese oxide catalyst, a $\mathrm{ZnO}$ phase formed as well as a zincochromite phase. By mass balance, it is likely that at least one other manganese containing phase existed also.

Regarding changes in catalyst structure during testing, ISS and XPS analyses were conducted on the Engelhard $\mathrm{ZnCrO}$ catalyst impregnated with $3 \mathrm{wt} \% \mathrm{~K}$.

ISS on the fresh catalyst indicated that the catalyst surface contained mostly oxygen in the outermost atomic layer. $\mathrm{Cr}, \mathrm{Zn}$ and $\mathrm{C}$ (impurity) were also observable. After reduction with hydrogen, the oxygen was removed and the primary component of the outermost surface became $\mathrm{K}$. $\mathrm{Zn}$ and $\mathrm{Cr}$ did not appear to be present on the surface, but $\mathrm{Zn}$ and some $\mathrm{Cr}$ and $\mathrm{Na}$ (impurity) were present after sputtering away the surface. After the catalyst had been used in the reactor to produce alcohols and hydrocarbons for about 5 days, $\mathrm{K}, \mathrm{Cr}, \mathrm{Zn}$ and $\mathrm{Na}$ were all evident on the surface of the catalyst. It is likely that $\mathrm{K}$ migrated to the surface during reduction, and $\mathrm{Na}, \mathrm{Zn}$ and $\mathrm{Cr}$ migrated to the surface during reaction.

XPS analysis indicated that the fresh catalyst contained primarily $\mathrm{Zn}$ and $\mathrm{O}$ (as $\mathrm{ZnO}$ ) in the near surface region. Trace peaks were observed for $\mathrm{Cr}$ and $\mathrm{C}$. There was no indication of a $\mathrm{Zn} / \mathrm{Cr}$ alloy. Adsorbed water, chemisorbed $\mathrm{O}$ and hydroxyl groups were also present. After reduction with hydrogen, the carbon and the hydroxyl groups diminished. $\mathrm{Zn}$ was still present as $\mathrm{ZnO}$, but there was also evidence of $\mathrm{K}_{2} \mathrm{Cr}_{2} \mathrm{O}_{7}$ or $\mathrm{KCrO}_{4}$ enrichment near the surface, in agreement with ISS results. Sputtering revealed that the potassium compounds were concentrated near the surface, and that some chromium oxide / hydroxide compounds were present beneath the K-rich layer. After use in the reactor for 5 days, chemisorbed $\mathrm{O}$ and hydroxyl groups increased significantly from $\mathrm{CO}$ dissociation and/or water gas shift reaction activity. $\mathrm{ZnO}$ was still the main zinc phase, but both $\mathrm{K}$ and $\mathrm{C}$ were absent (even after sputtering). Chromium oxide / hydroxide compounds were present near the surface.

XPS results support the idea that $\mathrm{K}$ migrates toward the surface during the hydrogen reduction step. During use, the $\mathrm{K}$ seems to be lost from the near surface, and appears only in the topmost monolayer. An important implication of this work is that catalyst pre-treatment under different reducing conditions (e.g. under $\mathrm{CO}$ or other $\mathrm{H} 2 / \mathrm{CO}$ ratios) could yield different surface compositions and, consequently, different catalytic activity. 


\subsubsection{Reaction Engineering}

The performance of the packed-bed membrane reactor is being evaluated using the BASF methanol-synthesis catalyst. Previously, a quantitative model has been developed incorporating 8 differential equations, one each for the four components, viz., $\mathrm{H}_{2}, \mathrm{CO}, \mathrm{N}_{2}, \mathrm{CH}_{3} \mathrm{OH}$, present on both the shell side and the tube side of the membrane. (Details of the model can be found in MS57). A previous fit of the model to the experimental results of the packed-bed membrane reactor with the BASF catalyst indicated that the deactivation of this catalyst may be significant and unaccounted for by the model. Accordingly, we fitted the conversion data to the form

$$
X(t, T)=X o \exp [-\beta / T] \exp [-\alpha t]
$$

where $X(t, T)$ is the conversion at time $t$ and temperature $T$. The values of $\alpha$ and $\beta$ were obtained from all catalyst samples at all flow conditions and temperatures, while values for $\mathrm{X}_{\mathrm{o}}$ were obtained for all temperatures at each flow condition. Values of $X_{0}, \alpha$ and $\beta$ are provided in MR59. Based on these values, the expected conversion for a fresh catalyst at each temperature can be obtained from:

$$
X(t=0, T)=X_{0} \exp [-\beta /(273+T)]
$$

These initial-conversion values, shown in MS60, were used to characterize the methanol-synthesis reaction in the packed-bed membrane reactor. Since all the flow conditions were carried out at least at one temperature, $250^{\circ} \mathrm{C}$, that temperature was used for the model.

Experiments to determine the values of the permeances independently have been carried out as described in MR57. These values were substituted in the model, and the differential equations were solved for each of the flow conditions at $250^{\circ} \mathrm{C}$ to obtain the conversions expected for a fresh catalyst under these flow conditions. These results show qualitative agreement between the model and the data; see MS60. However, it was considered possible that small changes in the values of the permeances could improve the correspondence between the model and the experiments.

Accordingly, an optimization routine has been written, using a simplex/complex procedure, to obtain optimum values of the permeances for the best fit to the (modified) experimental data. Preliminary results from the program indicate that the following set of values may be optimum:

$$
\begin{array}{ll}
\mathcal{P}_{\mathrm{H} 2}=0.2967 & \mathrm{~mol} / \mathrm{min} / \mathrm{m}^{2} / \mathrm{MPa} \\
\mathcal{P}_{\mathrm{CO}}=7.74 & \mathrm{~mol} / \mathrm{min} / \mathrm{m}^{2} / \mathrm{MPa} \\
\mathcal{P}_{\mathrm{N} 2}=8.7 \times 10^{-3} & \mathrm{~mol} / \mathrm{min} / \mathrm{m}^{2} / \mathrm{MPa} \\
\mathcal{P}_{\mathrm{MeOH}}=1.85 & \mathrm{~mol} / \mathrm{min} / \mathrm{m}^{2} / \mathrm{MPa}
\end{array}
$$

The optimized model and the modified experimental data have also been compared in MS60. Here the points are much closer together than when the independently-obtained values of the permeances were used. However, the program procedure depends critically on the choice of initial values of the parameters. Hence the numbers of Equation (3) need to be further verified. 


\subsection{Conclusions and Recommendations}

Reduced Mo-Ni-K/C materials continue to be considered as promising catalysts for HAS. The kinetic study using the Rotoberty reactor has been completed and analysis of the results is forthcoming. A model for the performance of a packed-bed membrane reactor in the synthesis of alcohols may be useful. Characterization of K-promoted transition-metal catalysts used in HAS shows the effects of the support and the aging process on these catalysts.

\subsection{Future Plans}

At WVU, we plan to continue the TPR experiments on carbon-supported Mo-based catalysts as well as the qualitative and quantitative analyses of the spectra. We are also continuing our kinetic studies on the reduced $\mathrm{Mo}-\mathrm{Ni}-\mathrm{K} / \mathrm{C}$ catalysts. We also plan to continue the investigations on sulfide catalysts. We expect to continue development of the kinetic model of the $\mathrm{Co}-\mathrm{K}-\mathrm{MoS}_{2} / \mathrm{C}$ catalyst used for HAS in the Rotoberty reactor, using only the statistically significant terms. However, the formation rate of methanol must be obtained by other than a simple power-law expression. We expect to complete the development of the model of the membrane reactor to explain the differences in the results with the conventional reactor. At UCC, additional characterization results for a Csimpregnated catalyst should be available soon to compare with these K-promoted catalysts.

\subsection{Introduction}

Work on the design and optimization portion of this task, as well as the fuel testing, is completed. All funds have been expended and there are no personnel working on this project.

Work on the fuel testing portion of the project has largely been completed. A manuscript reporting on some results is in preparation and will be included as an attachment on a future Quarterly Technical Progress Report.

\subsection{Accomplishments, Results, and Discussion}

\subsubsection{Fuel Testing}

There are none to report.

\subsubsection{Optimization}

There are none to report.

\subsection{Conclusions}

There are no conclusions. 


\subsection{Future Work}

Since all funds have been expended on optimization, fuel testing, and design and there are no personnel working on this portion of the project, no further work should be anticipated. 
M98051896

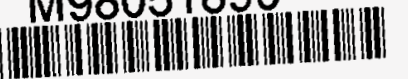

Report Number (14) DOE/PC $191034=-T 18$

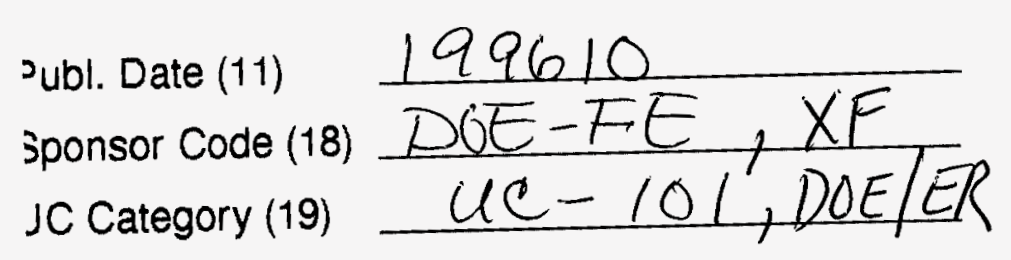

DOE 